\title{
LEYENDO A HÖLDERLIN
}

Diego Sheinbaum*

\section{La poesía y la ciudad}

Mirando a mis compañeros del seminario sobre Hölderlin recordé una extraña visión que había tenido hace diez años de un zoológico o reserva natural de poetas ¿Cómo habíamos llegado hasta aquí? ¿Nos había engañado una calurosa corriente de entusiasmo juvenil o le habíamos querido dar forma a un helado resentimiento? Mientras los veía bostezar sospechaba que habíamos olvidado las razones del vuelo. Nuestros párpados purpúreos, los cuerpos distendidos y los brazos fláccidos estaban impregnados de esa pereza propia de los animales en cautiverio. ¿Dónde estábamos? ¿Tenía algún papel la poesía en la ciudad? ¿Éramos simplemente una especie fuera del espíritu de los tiempos, protegida en una reserva que simulaba las condiciones originales de nuestro hábitat?

Estas preguntas no eran tan gratuitas en mí, tenían una historia. La política y la poesía aparecieron simultáneamente en mi vida como dos caras de una moneda, como el día y la noche, aunque sus papeles eran intercambiables. Alrededor de los deiciséis años descubrí la poesía como una especie de catacumba a la que descendía para regodearme en sus cámaras solitarias, en las bóvedas de sus palabras, en las sílabas que se deshacían alimentando esa identidad misteriosa. Por esas

\footnotetext{
* Exalumno de Ciencia Política, ITAM.
} 
mismas fechas, entre los libros de mi madre hallé uno que hablaba de las formas ideales de gobierno. Las esencias y ciclos que describían Aristóteles, Platón y Polibio me sedujeron de inmediato, tal vez por esa mirada taxonómica que veía los cuerpos políticos como si fueran grandes animales o tal vez por esa manera de destilar con una claridad embriagante los principios que movían a los hombres bajo diferentes regímenes. Política y poesía incitaban mi corazón con igual fuerza y ese impulso los unía en mi imaginación como posibles cónyuges. De esta confusión nacieron extrañas historias. Me acuerdo de haber escrito una sobre un niño de nueve años que mordía a su maestra en el patio de la escuela en nombre de los ideales de la Revolución Francesa.

Ahora en mi seminario de doctorado me daba cuenta de que los misteriosos e hipotéticos comercios entre mis dos musas me seguían intrigando. Lo más extraño no era el ambiente lánguido, propio de cualquier clase, sino el contraste con la agitación de los versos de Hölderlin. Frente al desfallecimiento con que se leían sus poemas yo sentía un temblor, una sacudida, algo que estaba apunto de romperse. Pero esta viveza no siempre brotaba de las páginas. El misterio sólo surgía en el anonimato, bajo la luz íntima, a puerta cerrada.

¿Qué encontraba en los poemas de Hölderlin? Es difícil describirlo. Algo fresco, un tímido rocío que hacía latir los cuerpos de las montañas y los árboles, que se convertía en el fluir transparente de los ríos. Las estaciones marchaban cada una a su ritmo. Sobre todo estaba el otoño, el tiempo de la maduración, la ofrenda y el sacrificio: las hojas tomando el color del ocaso. Sumergiéndome un poco más descubría esa misteriosa correspondencia entre los movimientos de la naturaleza y los del corazón humano; la canción del poeta era un eco de las silenciosas melodías de la vida y sus elementos. Pero si los versos de la primera época de Hölderlin me alcanzaban, los de las grandes elegías me remitían al misterio de su poesía. En ellos brillaba la oscuridad. Eran versos mojados en un vino antiguo, enigmático. Su embriaguez era lejana, triste, oceánica. En ellos Hölderlin alcanzaba esa dimensión mitológica; su poesía era un velo frágil, lleno de gracia y formas inesperadas, una tela que, en cuanto a su aliento cósmico 
podría atribuirse a Ovidio, pero tenía un ligero aroma a descomposición, a sombra, a sudario:
¿Vuelven las grullas hacia ti, y dirigen de nuevo los navíos su rumbo a tus orillas? ¿Acarician las brisas deseadas tus tranquilas aguas? ¿Y atraído desde lo profundo baña el delfín sus lomos en la nueva luz? ${ }^{1}$

Este hechizo desaparecía cuando leía las líneas en el seminario. Las imágenes se volvían pesadas, la sintaxis desvelaba sus articulaciones viejas, sus muecas retóricas, como si de las cabezas de los asistentes surgieran serpientes lustrosas, verdes, temibles. Nuestras miradas transformaban el gozo privado en sopor público, la ligereza y el vuelo íntimo en gravedad y lentitud compartida: ¿Demasiadas manos para un hilo tan fino? ¿Demasiados cazadores para lograr vislumbrar una criatura veloz, frágil, huidiza?

La experiencia en clase sólo confirmaba un sentimiento que me hacía rehuir las lecturas públicas de poesía $\mathrm{y}$, en general, cualquier acto público de literatura. Todos ellos tenían un halo de prédica, de oficiantes y feligreses. La figura del poeta ejerciendo en público me parecía completamente anacrónica. En cada uno de estos eventos se me revelaba el triste destino de la poesía que seguía el camino de las grandes religiones: no tenía lugar en el mundo, vagaba como un ridículo fantasma de otra época. A estas conclusiones llegué después, al rememorar mi experiencia en el seminario, pero mientras esperaba mi turno para leer no me resignaba: ¿Cómo podía evitar matar a Hölderlin en público? ¿Cómo no indigestar de hastío a mis compañeros? Había seleccionado un poema de juventud llamado El Viajero. Pensé hacer algo dinámico, esbocé un guión en el que aparecía un alemán con peluca blanca, ataviado con ropas anticuadas, leyendo poesía, sobre un fondo notoriamente contemporáneo, con turistas japoneses y una multitud enfebrecida realizando compras. Lo que quería era mostrar

${ }^{1}$ Friederich Hölderlin, El Archipiélago, 1979, Madrid, Alianza, trad. Luis Díez del Corral. 
de manera burda la distancia que había percibido en las lecturas en el salón de clases, el vacío de las palabras, el océano que nos separaba de Hölderlin y su época. Estas imágenes seguramente podrían hacer sonreír a alguno, pero, al mismo tiempo, con ellas perdía lo que consideraba más valioso de Hölderlin. Sólo traicionando su espíritu ganaba a los compañeros. Pero entonces, me asaltaba de nuevo la duda, ¿se podían traer las palabras de Hölderlin a nuestro tiempo o sólo era posible ir hacia él en lo oscuro de la noche, en su silencio?

\section{La generación de 1790}

¿Qué mundo pisaba Hölderlin? ¿Qué escenarios reales alimentaban los paisajes imaginarios por donde vagaba el viajero, esa figura tan frecuente de su poesía? El año 1790 aparecía en mi imaginación junto a la cabeza guillotinada de Luis XVI, que rodaba acompañada de los planetas y el manto de las constelaciones. El cauce completo de la creación se había desbordado de la vieja presa y cargaba también figuras menores como curas, campesinos y sirenas. Para mí eso era mil setencientos noventa:

82 el final de una época y el no menos caótico principio de una nueva. El viajero de Hölderlin nadaba entre los torrentes, llevado por fuerzas temibles pero también llenas de posibilidades.

La reacción inmediata frente a esta falta de forma la retrata Hölderlin en la primera versión de La Muerte de Empédocles; es lo que podríamos llamar el salto revolucionario que repetirían movimientos y vanguardias durante los siguientes dos siglos: la maroma por encima de las costumbres, de las leyes, hacia el contacto inmediato con la naturaleza y los hombres, una línea que cautivó a Occidente desde Rousseau hasta Jim Morrison.

Pero en las transformaciones de Empédocles comprobamos ese segundo camino que decidió tomar Hölderlin, y su generación. A la vía política, francesa, que había desembocado en el terror, respondieron con el camino espiritual y no político. Desde Schiller hasta Hegel decidieron que, antes de forjar instituciones, había que forjar valores; 
que la violencia de nada servía sin el convencimiento. Si Francia era la patria de la política, era el destino de Alemania llevar a cabo esta misión espiritual, educativa. En los Himnos de Tubinga encontramos ese canto embriagado a la libertad, a quien el poeta defendería frente a las mismas puertas del Orco. Sin embargo, no es la violencia lo que caracteriza estos versos sino una extraña humildad, un asombro ante las fuerzas del cosmos y la finitud del hombre.

Así el viajero de Hölderlin como figura emblemática de su generación tiene la extraña combinación de humildad y lucidez para ver las paradojas y contradicciones de la nueva época. Sabe que la libertad ha sido conquistada al provocar una herida en el orden. Para hacerse libres los hombres se han tenido que desvincular del resto de la creación. El premio de su madurez ha sido caerse del árbol de la vida. No por nada Hölderlin se refería a Kant como el Moisés que los había liberado y conducido al desierto para darles las nuevas y severas leyes, las tablas de la libertad radical: emancipación frente a la tradición, la sociedad y la naturaleza. ${ }^{2}$ Pero en medio del desierto, la generación de Hölderlin contempló por primera vez el costo de esta autonomía y entendió que su tarea - difícil y compleja- era reconciliarse con el orden, con los hombres y con la naturaleza.

Los términos de la síntesis fueron identificados de maneras variadas. Para Friedrich Schlegel la tarea era unificar a Goethe y a Fichte, la poesía del primero representando lo más alto en belleza y armonía; la filosofía del segundo era la declaración más plena de la libertad y sublimidad del yo. Otros como Schleiermacher y Schelling hablaban de unir a Kant y a Spinoza. Pero una de las formas más comunes era plantear la cuestión en términos históricos, como el problema de unir lo más grande antiguo con lo más grande moderno. De esta manera se presentó el problema para Schiller, Hegel y Hölderlin, que, como muchos alemanes de esta generación, veían en los griegos la más perfecta unión entre naturaleza y la más alta forma de expresión humana.

${ }^{2}$ Hölderlin, Correspondencia Completa, 1990, Madrid, Hiperión, trad. Helena Cortés Gabaudan, p. 405. 
Pero esta unidad había muerto. Y más aún, tenía que morir, pues era el precio del desarrollo de la razón a la más alta cumbre de la autoclaridad, necesaria para la realización de seres radicalmente libres. ${ }^{3}$

En este camino de retorno la filosofía de Herder es tan importante como la filosofía de Kant en el sentido contrario. Herder critica las separaciones falaces y artificiosas entre razón y sensibilidad, voluntad y naturaleza, cuerpo y alma, y así se convierte en la punta de lanza de la rebelión romántica. La suya es una revuelta contra el Estado y la división del trabajo, las cuales transforman al individuo en un triste fragmento, amputando sus capacidades, dividiendo la sensibilidad de su pensamiento, convirtiéndolo en un engranaje del sistema. ${ }^{4} \mathrm{Hölderlin}$ seguirá a Herder en la importancia que atribuye a la expresión como vehículo de la unidad. Lo que hacen las artes de manera explícita y, de manera implícita las demás obras de los hombres, es eso: expresar la irreductible individualidad de cada ser humano y de cada cultura. Lo que encontramos en ellos, no son productos, sino voces.

Herder arremete contra la noción cartesiana del lenguaje como un mero instrumento del intelecto. Palabras y pensamientos no están separados. Los hombres no piensan en ideas y nociones y después buscan las palabras para arroparlas, como si se tratara de buscar un guante para una mano completamente formada. Herder legará a la

3 "El intelecto estaba inevitablemente compelido a disociarse del sentimiento y la intuición en el intento de arribar a un entendimiento discursivo más exacto", como lo plantearía Schiller en la sexta carta De la Educación Estética del Hombre, añadiendo que si las diferentes potencialidades del hombre iban algún día a desarrollarse, no había otro camino que lanzarlas unas contra otras: "este antagonismo de fuerzas es el gran instrumento de la cultura", Charles Taylor, Hegel and Modern Society, 1979, London, Cambridge University Press.

${ }^{4}$ Isaiah Berlin rescata el olvidado individualismo de Herder para quien la originalidad, la libertad de elección y la creación son elementos divinos en los hombres. En esta misma corriente encontraríamos a Schiller, Mill, Carlyle o Ruskin. Schiller diría: "Una práctica unilateral de las facultades humanas conduce al individuo inevitablemente al error pero conduce a la especie hacia la verdad. Sólo reuniendo toda la energía de nuestro ser en una sola de nuestras facultades, damos alas a esa facultad y la llevamos artificialmente mucho más allá de los límites que la naturaleza parece haberle impuesto [...] [lo que nos convierte] en los siervos de la humanidad e imprime en nuestra naturaleza mutilada las huellas de la vergonzosa esclavitud, en La Educación Estética del Hombre, 1981, Madrid, Aguilar, Carta Sexta, trad. Vicente Romano García. 
generación de 1790 la doctrina del lenguaje de Hamman. El lenguaje es el órgano central del entendimiento, la actividad fundamental del hombre es hablar a otros (a otros hombres, a Dios, a ellos mismos). Así el lenguaje no es, como mantenía Condillac, un instrumento que el hombre desarrolló en un determinado momento histórico. El lenguaje es un crecimiento natural -no menos ni más misterioso que cualquier otro desarrollo natural. Dios -si uno creía en él- había dado al hombre una naturaleza capaz de actividad mental, el poder de generar símbolos, de comunicación, de intencionalidad. A través de vincular las pasiones con las cosas, el presente con el pasado, de hacer posible la memoria y la imaginación, las palabras crearon la sociedad, la literatura y la historia. ${ }^{5}$

Al mismo tiempo, Herder encabeza la rebelión relativista contra el universalismo ilustrado. No es cierto que exista una Humanidad. No hay una naturaleza humana más allá de las variaciones culturales. No todos los hombres tienden hacia un mismo ideal y, por lo tanto, diversas culturas no deben ser juzgadas por un mismo criterio. Cada cultura tiene un centro de gravedad y el historiador para conocerla necesita de la ayuda de la imaginación, de un salto a través de la simpatía, necesita viajar para situarse en lo pies del otro. ${ }^{6}$ Esta distancia entre culturas tendrá una gran importancia en la transformación del paisaje que recorre el viajero de Hölderlin. Por medio de ella se puede percibir el cambio en su concepción de la poesía y el papel del poeta moderno.

${ }^{5}$ Cfr. Isaiah Berlin, "Herder and the Enlightment", en The Proper Study of Mankind, 1998, New York, Farrar, Straus and Giroux.

${ }^{6}$ Ibid. Herder es un pensador hechizado por el misterio de la creación humana, tanto individual como colectiva. Se suma en nombre de este misterio a la crítica de Montesquieu contra los grands simplificateurs, contra la disección que asedia a la sensibilidad, contra la ceguera de las lumiers, incapaces de ver el espíritu interior de cada sociedad, de cada época, de cada individuo. Tratar de imponer clasificaciones tan rígidas en manifestaciones tan complejas y variadas, ya sea por filósofos buscando el conocimiento o gobernantes buscando organizar, es quedarse en el denominador común más bajo y, por lo tanto, ocuparse de lo vacío en la teoría e imponer en la práctica la uniformidad. 


\section{El poeta como nadador}

En los primeros poemas de Hölderlin encontramos al viajero marcado por la maldición kantiana: vagar sin un destino claro, fuera de la comunidad, del orden natural, de la unidad primigenia, extranjero que intenta retornar a casa. A través de su lira el poeta logra la anhelada comunión. Esta idea -la expresión como forma de completar la naturaleza- es parte del arsenal conceptual que desarrolló la generación de 1790. Es una versión sofisticada de la idea renacentista del hombre como microcosmos. El hombre no sólo refleja el orden de la naturaleza sino que al expresarlo lo completa, lo hace consciente.

Esta es una operación mucho más compleja. Para lograrla fue indispensable dotar de una espiritualidad a la materia (de la cual Kant la había despojado), de tal forma que estos primeros románticos concibieron el espíritu que anima a las cosas con un ímpetu propio y natural hacia la libertad. Hölderlin lo plantearía en los siguientes términos: "[Acercarse a este ideal] no es pensable sin la fe en un señor de la naturaleza cuya voluntad quiere lo mismo que nos ordena la ley moral que hay en nosotros [...] que alberguemos la fe de que las cosas, incluso allí a donde no llega el poder de nuestra voluntad [...] trabajan sin embargo en perfecta comunión para alcanzar esa meta." Mientras se pensara en la naturaleza en términos de fuerzas ciegas o de hechos brutos era imposible lograr la fusión con lo racional, con lo autónomo en el hombre. Si bien esta concepción se acerca a las visiones panteístas que ven el mundo como emanando de un subjetividad cósmica, este panteísmo no podía proveer la base para unir autonomía y unidad expresiva. Porque si el hombre sólo es una parte infinitesimal de la vida divina que fluye a través de toda la naturaleza, la comunión con el Dios de la naturaleza sólo significaba entregarse a la gran corriente de vida y abandonar la autonomía radical. Así, la idea de esta generación que provenía de Herder y de Goethe no era un simple panteísmo, sino una variante renacentista de la idea de hombre como microcosmos. El hombre no sólo es una parte del universo, sino que refleja el todo. El 
espíritu que se expresa en la realidad externa de la naturaleza alcanza una expresión consciente en el hombre. Schelling diría que el principio creativo de la naturaleza y el poder creativo del pensamiento son uno. Hay dos ideas recurrentes que pasan de Goethe a los románticos: sólo podemos conocer a la naturaleza porque estamos hechos de la misma sustancia y sólo podemos conocerla propiamente cuando entramos en comunión con ella, no cuando intentamos diseccionarla o dominarla para sujetarla a las categorías de nuestro entendimiento analítico. Pero entonces, ¿cuál es nuestra relación en tanto espíritus finitos con la fuerza creativa que subyace a la naturaleza? ¿Qué significa decir que es una con nuestro poder creativo de pensamiento? ¿Significa únicamente el poder de reflejar en la conciencia la vida que ya está completa en la naturaleza? ¿En qué sentido sería esto último compatible con nuestra libertad radical? ¿Sería la razón una fuente autónoma de norma si nuestro más alto logro es expresar fielmente el orden más grande al que pertenecemos? Lo que estaba en juego era la conquista kantiana, la madurez de la humanidad. Para salvar este principio tan caro de la autonomía radical había que empujar un poco más lejos la idea de microcosmos. La conciencia humana no sólo refleja el orden de la naturaleza sino que lo completa y lo perfecciona. Desde esta perspectiva, el espíritu cósmico que se desenvuelve en la naturaleza está buscando completarse en la conciencia como conocimiento de él mismo. El lugar de este autoreconocimiento es la mente humana. ${ }^{7}$

¿Qué serían, por tanto, el cielo y el mar,

las islas y los astros, y todo lo que se ofrece

a la vista de los hombres? ¿Qué sería de

esta lira, si yo no le prestara la voz,

la lengua, el alma? ¿Qué son

los dioses y su espíritu, si yo

no los enunciase? ${ }^{8}$

${ }^{7}$ Cfr. Charles Taylor, Hegel and Modern Society.

${ }^{8}$ Friedrich Hölderlin, La Muerte de Empédocles, 1983, Madrid, Hiperión, trad. Carmen Bravo-Villasante, p. 145. 
Hasta la segunda versión de La Muerte de Empédocles, es decir hasta el año 1799, encontramos que la unión entre naturaleza y hombre se da en términos radicales, podríamos decir, revolucionarios. El poeta oscila entre una alienación total y una identificación completa (tanto con los dioses como con los hombres y la naturaleza). No hay mediación ni claroscuros, sólo luz y oscuridad. Grecia no se distingue de Alemania, ni el pasado del futuro. Sin embargo, a partir de 1800, hay un giro notable en la poesía de Hölderlin. De pronto, sus palabras toman una nueva densidad, como si una nueva concepción del tiempo y de la historia cubriera los paisajes y los nombres griegos de neblina; a pesar del esfuerzo del poeta, sus voces y sus ritmos parecen alejarse hacia el silencio. Antes, en los versos de Hölderlin, la relación del poeta con el mundo había sido gobernada por la inmediatez y la causalidad. El poeta era un profeta que actualizaba la unidad perdida. La relación con el tiempo, con el pasado y el futuro, no reclamaba ninguna acción. ${ }^{9}$ Pero a partir de 1800 hay un cambio en la concepción de Hölderlin de la historia. El viajero ya no vaga por los alrededores sin un destino. En su lugar encontramos la figura del poeta como un nadador. Así, el exilio del poeta es un viaje más allá de las concepciones de su tiempo, de la tierra firme de sus contemporáneos. El nadador se lanza a las aguas, remonta la corriente del tiempo, avanza contra el fluir inevitable del río de Heráclito:

¿Dónde estas Atenas, dime? ¿Se redujo a cenizas, ¡enlutado dios!, cubriendo las urnas de los grandes antiguos, tu ciudad,

${ }^{9}$ Cfr. Glenn W. Most, "Hölderlin and The Poetry of History", The Germanic Review 61, 4, Otoño 1986, p. 154-67. De esta manera Hölderlin respondía a su tiempo, se incorporaba al viaje del espíritu que había iniciado en el exótico Oriente, pasando por Grecia, Roma, el Renacimiento, hasta llegar en la Edad Moderna a Europa del Norte. Este modelo - que se puede llamar la occidentalización del espíritu- fue un doble lujo que se permitió la generación de Hölderlin. Más allá de que este modelo sólo comprendiera a las culturas cercanas al Mediterráneo, más allá de las carencias de su movimiento simple y diacrónico, les permitió cubrir una necesidad importante: que el reconocimiento del pasado no supusiera una descalificación del presente, afirmar la plenitud antigua pero también su inevitable declive. La Querelle des Anciens et des Modernes había planteado la cuestión en términos de una elección estéril: ir tras la belleza clásica perdiendo el derecho de la poesía moderna o renunciar al gran valor reconocido de la literatura antigua para afirmar lo moderno. 
la que tú más amabas, en las sacras orillas?

¿O existe aún algún indicio suyo, para que el navegante, cuando pasa, le recuerde y la nombre? ${ }^{10}$

El poeta deja de ser el revolucionario que tiene una relación de causalidad e inmediatez con lo que le rodea para convertirse en un historiador, un intérprete que se enfrenta a signos. De la revelación pasa a la hermenéutica, de ser un profeta que salta por encima de la tradición y las costumbres pasa a ser un traductor que busca los significados perdidos en los fragmentos de las tablillas.

La figura del nadador en el océano condensa el ideal de Hölderlin del poeta moderno. Con toda su finitud el hombre se aventura por la infinitud del mundo; el arte - en tanto formación, construcción y orden-se abandona a la vida informe, no organizada. Hölderlin ha comenzado a caminar hacia el mar, ha intuido como proyecto sumergir lo subjetivo en lo objetivo, hasta el extremo de que el hombre sea pura sensibilidad del objeto y el objeto tome una forma de conocimiento subjetivo:

Su espíritu tenía que adoptar figura aórgica en el más alto sentido, arrancarse de sí mismo y de su punto medio, penetrar siempre su objeto de modo tan desmesurado que se perdiese en él como en un abismo; [...] la entera vida del objeto tenía que apoderarse del ánimo abandonado -que por la ilimitada actividad del espíritu, no ha hecho otra cosa que volverse infinitamente receptivo [...] Y así el conflicto del arte-el pensar, el ordenar del carácter formante del hombre- y la naturaleza carente de conciencia, apareció resuelto, en sus extremos más extremos reducido a uno y unificado hasta la equivocación de la mutua forma distinguiente. ${ }^{11}$

Esta expresión había sido ya planteada en términos menos dramáticos por Schiller como el peligro de que la dimensión fluida, irregular, dinámica de la experiencia intentara ser dividida por el intelecto antes de percibir su infinitud, su multiplicidad. En Schiller, el papel de la

${ }^{10}$ Hölderlin, El Archipiélago, op. cit.

${ }^{11}$ Hölderlin, "Fundamento para el Empédocles", Ensayos, 1990, Madrid, Hiperión, trad. Felipe Martínez Marzoa, p. 113. 
cultura se vuelve justamente vigilar tanto al impulso sensible como al formal, para no sólo defender la sensibilidad de la razón, sino más importante para su época, defender la frontera de la sensibilidad de las invasiones de libertad o razón. Lo que busca Schiller no es tanto la confrontación como la coordinación y subordinación recíproca de ambos impulsos al reconocer que están dirigidos a objetos diferentes. Mientras que la sensibilidad tiene por objeto el mundo que es la extensión en el tiempo, la variación, la multiplicidad, la libertad tiene por objeto el yo, por lo tanto intenta imponer la personalidad, la coherencia, la permanencia frente a los cambios. El ideal schilleriano es la sensibilidad más abierta que pueda recibir más mundo y que se conjugue con la razón más autónoma que, por medio de su impulso enérgico y profundo, intente comprender la mayoría de los fenómenos. En los términos expuestos en la carta trece podemos comprender cómo el Empédocles está buscando este equilibrio y cómo a partir de esta obra Hölderlin comienza un camino mucho más receptivo, en el que se entrega a sus sentidos, hasta que el mundo cobra esa fuerza propia del mito que termina en última instancia destruyendo la personalidad. Las palabras de Schiller parecen un diagnóstico profético del estado que terminará por dominar a Hölderlin, al afirmar que si el impulso sensible se hace determinante, los sentidos imponen su ley y el mundo somete a la persona; entonces el mundo deja de ser objeto en la misma medida que se transforma en un poder. Si el hombre es sólo contenido del tiempo, entonces no es él, y por consiguiente tampoco tiene contenido. Con su personalidad también se suprime su estado (de ánimo), porque ambos son conceptos recíprocos, porque la variación requiere de algo permanente y la realidad limitada requiere una realidad infinita.

Los Fundamentos para la tragedia de Empédocles son el último peñasco. Hölderlin ha dejado los grandes vuelos filosóficos. Entre las nubes quedan la bandada de amigos que soñaban con una mitología de la razón. A partir de este momento comienza su nado por el mar. Como una criatura más humilde, un pez o un delfín, Hölderlin se abandona a su sensibilidad en ese medio fluido, dionisiaco, de las 
figuraciones y desfiguraciones. A sus espaldas queda el continente de la razón. Este cambio profundo viene acompañado de la nueva actitud respecto al tiempo, el pasado y la tradición. Esto se muestra en el fracaso de escribir una tragedia moderna (Empédocles), seguida por sus exitosas traducciones de Sófocles. Pero vale la pena detenerse en ese momento dramático, en que primero transforma y, después, abandona su proyecto de La Muerte de Empédocles. Alrededor de sus tres tentativas hay una serie de evidencias, rescatadas por Glenn W. Most, que apuntan a su nueva actitud: al vuelo que se convierte en nado, al ave que se transforma en pez.

En el invierno de 1799 Hölderlin escribe la segunda versión de dicha tragedia en un cuaderno, de la última página hacia la primera. Alrededor de la línea 154 suspende su trabajo, le da la vuelta al cuaderno y comienza con una traducción de Píndaro. La escritura se convierte en el nado que trata de salvar la distancia entre las dos orillas, la moderna y la antigua. Por si fuera poco como testimonio, en medio de esta labor, Hölderlin comienza la traducción de un poema de Ovidio. Se trata de la carta de Hero a su amado Leandro, quien fuera el más famoso nadador de la antigüedad. Todas las noches Leandro se lanza al mar mientras su amada deja prendida una antorcha en lo alto de un monte en Asia para iluminar su camino. En la figura del nadador podemos vislumbrar ya al Hölderlin de la tercera y última versión del Empédocles y de los Fundamentos. En esta última versión no sólo las imágenes del mar son mucho más frecuentes sino que aparece esa nueva figura, Manes, como encarnación de la tradición literaria, esa antorcha distante que guía al nadador en la oscuridad de su camino. ${ }^{12}$

Con la imagen del océano y el nadador Hölderlin provocará un gran impacto en los siguientes ciento cincuenta años de la literatura alemana. No sólo será una imagen que tendrá una gran significación para poetas como Rilke y Paul Celan, sino en otros ámbitos. Si bien las imágenes náuticas son recurrentes en la tradición literaria desde hace siglos (a veces como figura de la contingencia inevitable que supone

${ }^{12}$ Most, idem. 
la condición humana, o los obstáculos e incertidumbres que siempre se interponen entre el hombre y su deseo, o la ausencia de un piso metafísico), lo que está detrás del poeta como nadador que remonta las aguas hacia el pasado es la propia condición moderna respecto a la tradición, ${ }^{13}$ pues la caída del Ancien Régime supuso el derrumbe del puente que comunicaba el pasado con el futuro. Al dejar tras nosotros el barandal de la tradición, dejamos esa importante función de seleccionar y nombrar que ésta cumplía. Por eso, junto con esta imagen, a la vuelta del siglo XVIII, Hölderlin se da cuenta de que las palabras están desgastadas, sus cuerpos que alguna vez fueron habitados por un espíritu son conchas vacías, fósiles que no pueden ser tomados por seres vivientes. Los conceptos latinos con los que se había cubierto la continuidad de dos milenios, desde Roma hasta la Edad Moderna, se habían endurecido, cristalizado; había que lanzarse hacia el pasado para descubrir su significado. Su poesía se vuelve el acto de traer lo irrecuperable al presente, no para actualizarlo, sino para mostrar su imposibilidad. De ello surge, por contraste, nuestro nuevo rostro, en tanto modernos, nuestra necesidad de hundirnos en la experiencia para que surjan las palabras de ella como burbujas en el mar:

Y tú, inmortal, aunque no te festeje

la canción de los griegos, como antaño, resuena a menudo, ¡oh dios del mar!, en mi alma con tus olas, para que sobre las aguas prevalezca sin temor el espíritu, como el nadador, se ejercite en la fresca dicha de los fuertes. ${ }^{14}$

\section{Animales de zoológico}

Durante los siguientes dos siglos hombres de los más distintos perfiles siguieron albergando esa pulsión que sintieron los contemporáneos de Hölderlin de adecuar el espacio de la ciudad a la poesía, de darle a la

${ }^{13} \mathrm{Idem}$.

${ }^{14}$ Hölderlin, El Archipiélago. 
razón esa corporalidad del mito, lo cual sólo provocó mutilaciones, desfiguraciones y tragedias de gran escala. Es curioso, sin embargo, que Hannah Arendt comenzara su reflexión sobre el totalitarismo y los campos de concentración realizando esa labor hölderliniana, de regresar al pasado para remontar los conceptos muertos de las ideologías y encontrar el espíritu perdido de nuestro vocabulario político más básico. Pero no es a la poesía o al mito a lo que apunta la reflexión política de Arendt, sino, justamente, a la experiencia, lejos de los dictados del mito y la historia. Las consecuencias de buscar certidumbres para la experiencia en el pasado o en el futuro nos las muestran muchos de sus contemporáneos que prefirieron quedarse en los terrenos mitológicos o en las mentiras baratas que difundían las células del partido, quedarse en ese tiempo pétreo de la ideología, lo que suponía, no una maldad como lo muestra el juicio de Eichmann, sino una especie de muerte cerebral, por empalamiento. Estas situaciones cumplieron tristemente las profecías de Herder y Schiller. Sensibilidad y pensamiento se despidieron en las estaciones de trenes que viajaban hacia el este. Sobre Europa el hombre fue un triste fragmento, un engranaje del sistema. Eso era lo que reveló la figura de Eichmann a los ojos de Arendt. En su rebeldía contra la condición moderna, el hombre del siglo XX había tratado de construir avenidas allí donde sólo había fragmentos, había tratado de ampararse en procedimientos donde sólo había incertidumbres.

Para nosotros, los que asistíamos al curso de Hölderlin, este tiempo de los bloques que sepultaban el pensamiento había quedado afortunadamente atrás. Para nuestro beneficio, el pasado, el nombrar, había vuelto a ser una responsabilidad de cada quien, una batalla -a veces abierta, a veces encubierta, y siempre confusa- dentro de los muros de la ciudad. Y mientras las diferencias entre la generación de Arendt y la mía me quedaban claras, me convencía más que la única posibilidad de sobrevivir de la poesía era más allá de la mirada pétrea del espacio público.

Además, ¿por qué debería ser diferente?, ¿por qué el destino de la poesía debía ser distinto al de los animales y los dioses?, ¿el precio de 
entendernos racionalmente no había supuesto desde un principio dejar a estos fabulosos seres en los límites de la ciudad? Y sin embargo, mientras que el curso llegaba a su fin y yo seguía disfrutando la enorme individualidad que la poesía permitía y fomentaba, había algo en mí que no podía resignarse a dejarla en este papel tan íntimo. A veces se lo achacaba a la fiebre rabínica y comunista de mis abuelos que, como una materia espesa, no se diluía en mis venas. Fuera como fuera, me seguía preguntando cómo traducir esa felicidad privada en una felicidad pública. Tal vez, la respuesta estaba en la humildad y lucidez de Hölderlin. Después de todo, ¿no se trataba de habitar ese lugar en los límites de la ciudad? ¿De recordar desde ahí la ligereza e invisibilidad de las riquezas entre las que vivimos? Tal vez el papel de la poesía seguía siendo el mismo: entrar sigilosamente en la ciudad, murmurar algunas palabras para recordarnos el placer del pensamiento y la palabra libre. Pero no más. Había que entrar y salir rápido, viajar de cabeza a cabeza, de boca a oído. La poesía sólo podía ser una gacela, una brisa, no un monumento. Su papel era humilde, solitario, y requería esfuerzo, ejercicio, brazadas en el mar. La fragilidad y la magia de las palabras podían desaparecer, como los dioses de Hölderlin, en el océano, si de vez en cuando una voz no intentaba evocarlas; si alguien a través de los barrotes no se dejaba llevar por ese extraño aliento, por ese poder enigmático, por esas voces que no son nuestras. 